


\title{
A RELAÇÃO ESCOLA-PAIS: UM MODELO DE TROCAS E COLABORAÇÃO
}

\author{
ELIANA BHERING \\ Mestre e doutoranda pelo Child Development \& Learning - Institute of Education - University of London e \\ Professora do Curso de Psicologia da UNIVALI
}

\section{IRAM SIRAJ-BLATCHFORD}

Professora convidada do Child Development \& Learning - Institute of Education - University of London

\begin{abstract}
RESUMO
Este estudo usa dados qualitativos coletados em entrevistas com um grupo de 21 "pais" de crianças de $4^{\circ}$ série do 1 g grau, em oito escolas estaduais de Belo Horizonte, Minas Gerais. O objetivo foi o de pesquisar sua opinião sobre seu envolvimento com a escola primáría e com aspectos educacionais. Os dados foram coletados utilizando a tipologia criada por Epstein (in Brandt, 1989), na qual foram resumidas em cinco categorias as várias maneiras de envolver os pais com a escola. Esta tipologia tem sido usada em várias pesquisas, em diferentes países e sua validade já se encontra testada cientificamente. Étambém usada a teoria das esferas sobrepostas (Epstein, 1987). Os resultados mostram o surgimento de um modelo diferente do de Epstein, que pode ser resumido em três categorias: ajuda, comunicação e envolvimento. A nossa definição de "pais" inclui mães, pais, e todos os outros responsáveis pela guarda legal da criança, mas isso não implica a participação de pais neste estudo, pois nele prevaleceram mães que costumam ser mais presentes na escola, tanto no Brasil como em outros países. RELAÇÕESESCOLA-FAMIILIA-ESCOLAS-RELAÇÕESPAIS-ALUNOS
\end{abstract}

\footnotetext{
ABSTRACT

THESCHOOL-PARENTRELATIONSHIP-ACOLLABORATIONANDEXCHANGEMODEL. This study uses data from 2 I fourth grade parents in 8 Brazilian state pre-and primary schools in Belo Horizonte - MG, Brazil, to examine their views about parental involvement and others issues related to their children's school education. The data has been collected through using Epstein's typology (in Brandt. 1989). This typology has already been validated in the past and it was created to summarise many of the kinds of parental involvement practices that any level of schooleducation - from nursery years to secondary level-may develop. A different pattern of the parents and the schools relationship emerged from the parents' data analysis if put in contrast with Epstein's parental involvement typology (1987). The pattern can be unfolded in three variations described as help, involvement and communication. A semi-structured questionnaire was used to conduct the interview with the parents. This article does not intend to analyse the present situation of the contemporary family but we acknowledge the fact that there are different family structures in our modern world and that they may influence parental involvementresults.
} 
O envolvimento dos pais com a escola é, hoje em dia, considerado como um componente importante para o desempenho ideal das escolas e, portanto, os investigadores e autores o consideram como merecedor de uma atenção especial e acentuada. Os pais mais freqüentemente as mães - passaram a fazer parte daqueles elementos-chave que contribuem para a obtenção de melhores resultados na escola e até mesmo em termos comportamentais. Joyce Epstein (1987) nomeia estes elementos-chave como: o ensino, o curriculum, as instalações (incluem materiais, equipamentos e pessoal) e também os pais. Mortimore et al. (1988) também incluem os pais na sua lista de doze variáveis organizacionais como um componente importante e imprescindível numa escola que visa maximizar o sucesso escolar.

O envolvimento de pais não só contribui com todo o processo escolar (tudo que isso implica) como também contribui para uma melhoria dos ambientes familiares (no sentido de provocar uma maior compreensão do processo de crescimento e, portanto, da aprendizagem das crianças) e eventualmente poderá influenciar positivamente o curso do desenvolvimento das crianças, como o rendimento escolar. Muitas pesquisas (Smith, 1980; Epstein; 1986; Wolfendale, 1992, e outros) têm nos mostrado que, com a abertura das escolas para os pais, percebe-se uma mudança positiva na atitude para com a escola não só da parte das crianças como também deles mesmos. Dessa mudança tem nascido grandes iniciativas para o envolvimento mais sistemático e organizado dos pais em vários aspectos escolares. Apesar de grandes dificuldades serem encontradas nesta jornada, os resultados têm sido animadores. Bastiani (1993) afirma que "o envolvimento de pais com a escola passou a ser considerado nos últimos anos como uma preocupação necessária e legítima e não pode ser mais uma opção extra" que as escolas poderiam ou não ter. Isso não parece ser diferente na nossa realidade brasileira, pois estudos nacionais salientam a importância do contato com os pais em outras situações que não sejam somente em situações extremas e problemáticas (Pinheiro, apud Ferraz, 1986; Falcão Filho, 1989; Smolka, 1989; Pinto, 1985).

Somado a isso (a resultados positivos e a aceitação geral de que os pais podem ajudar a reverter alguns fracassos escolares), assistimos também a uma mudança rápida da nossa sociedade atual e não só a brasileira. Temos sido levados a agir rapidamente e adequar as nossas competências e serviços às necessidades da comunidade em que vivemos e servimos. A família, em decorrência dos avanços sociais, econômicos e tecnológicos, tem mudado os seus papéis, suas obrigações e sua estrutura tradicionais. Mães e pais tem cada vez mais negociado entre si as tarefas domésticas e responsabilidades no geral. A escola tem também avançado para oferecer aos alunos uma educação pertinente à nossa época. A aproximação das duas instituições é também uma tentativa de rever esses papéis tradicionais e, acima de tudo, visando melhorar a condição de vida e educação das nossas crianças. Essa parece ser uma tendência pouco realista quando nos deparamos com uma realidade que muitas vezes 
não nos permite e não nos dá condições favoráveis para fazer o processo de envolvimento de pais se desenvolver tão coerentemente.

Lareau ( 1987), depois de estudar a relação família-escola em duas escolas inseridas em comunidades de classe média alta e outra de classe trabalhadora, concluiu que as escolas (principalmente as que atendem às classes mais baixas) tinham visões e opiniões préestabelecidas sobre o papel que os pais poderiam ter no processo escolar. Não só isso, como também concluiu que as diferentes classes sociais provêem os pais com condições desiguais tanto no sentido do nível de resposta ao que os professores pedem/sugerem aos pais que façam (colaborem, ajudem ou se envolvam), como também nas condições criadas em casa que auxiliam, mais ou menos, a aprendizagem em geral. As características da família (como, por exemplo, as ligações sociais, número de membros, etc) também parecem influenciar na relação escola-família. Esses resultados nos alertam para pontos importantes que devem ser cuidadosamente considerados quando programamos o envolvimento de pais. Esses resultados também nos mostram que o envolvimento de pais pode variar de intensidade, nível e tipo de acordo com as "culturas" da escola e da comunidade a ser servida.

Muitos estudos (Jowett, 1988, 1991; Cyster et al. 1979; Epstein, 1986; Wolfendale, 1983 e outros) foram realizados, principalmente nas duas últimas décadas, que nos fornecem exemplos de diferentes maneiras para envolver os pais com a escola e com a aprendizagem (e às vezes com o ensino). A literatura neste tópico também nos indica que o envolvimento de pais não só é importante para um diálogo mais aberto entre os pais e professores e os pais e seus filhos e entre a tríade pais-criança-professores, mas também é vital para que os pais compreendam os objetivos da escola (meta considerada de extrema importância), o desenvolvimento das crianças e o processo educacional, assim como a atuação do professor como provedor de situações que viabilizam a aprendizagem. Além disso, visamos sempre que as crianças aprendam a utilizar os seus potenciais da maneira mais satisfatória possível com base em instruções dadas e situações criadas pelos pais e professores de maneira coerente e interligada.

Epstein ( 1987) elaborou um diagrama que retrata a relação escola-família englobando todos esses pontos e ainda acrescenta a contribuição de cada parte desta relação. As "esferas sobrepostas" (the overlapping spheres) representam a família e a escola atuando em favor da criança.

Segundo Epstein (1987), a força A representa o tempo em relação a faixa etária da criança como também a época, no sentido histórico da palavra. De acordo com o autor, o grau de sobreposição das esferas vai estar sempre relacionado com os valores e conceitos da época em que vivemos, com a idade da criança e a série em que ela está.

A força B representa a contribuição dos pais (o que querem, pedem ou dão dentro de suas filosofias e experiências de vida) para a sobreposição ou separação das esferas. A força C representa a filosofia, experiências, práticas, métodos e influências dos professores que, por sua vez, também contribuem para a movimentação das esferas. Ambas as forças criam um 
modelo dinâmico do relacionamento entre os professores e pais, que tanto pode ser num processo contínuo da relação, que será influenciado pelo momento educacional em questão (a série em que a criança está, sua idade, dificuldades etc) quanto com o surgimento de novas necessidades e, portanto, novas maneiras de participação e envolvimento. Apesar de haver um ajuste constante no jogo de sobreposição e separação das esferas, uma mudança drástica ou um abandono das práticas e do contato entre escola e família, e por qualquer uma dessas partes, significará uma quebra no sistema das esferas. Em outras palavras, o envolvimento de pais requer sempre uma revisão e avaliação do processo de envolvimento para que não haja quebras e falhas no sistema, mas sim uma flexibilidade crescente para mudanças, de acordo com o que é necessário (as demandas de todas três partes) para o funcionamento adequado do sistema. As forças A, B e C são interdependentes e precisam trabalhar juntas. Epstein ( 1987) descreve este sistema como "uma divisão das responsabilidades" entre as partes responsáveis pela educação e bem-estar das crianças e que possui um caráter mutável. É também importante ressaltar que Epstein propõe um modelo de envolvimento que não discrimina o envolvimento dos pais ou das mães. Ambos são vistos como parte integrante da família (e, em muitos casos, estas podem ser de natureza não nuclear, constituída só por mãe ou só por pai) e, portanto, ambos, ou um dos dois (caso a família seja nuclear), são bemvindos. $\bigcirc$ importante é proporcionar condições cada vez mais favoráveis ao desenvolvimento infantil.

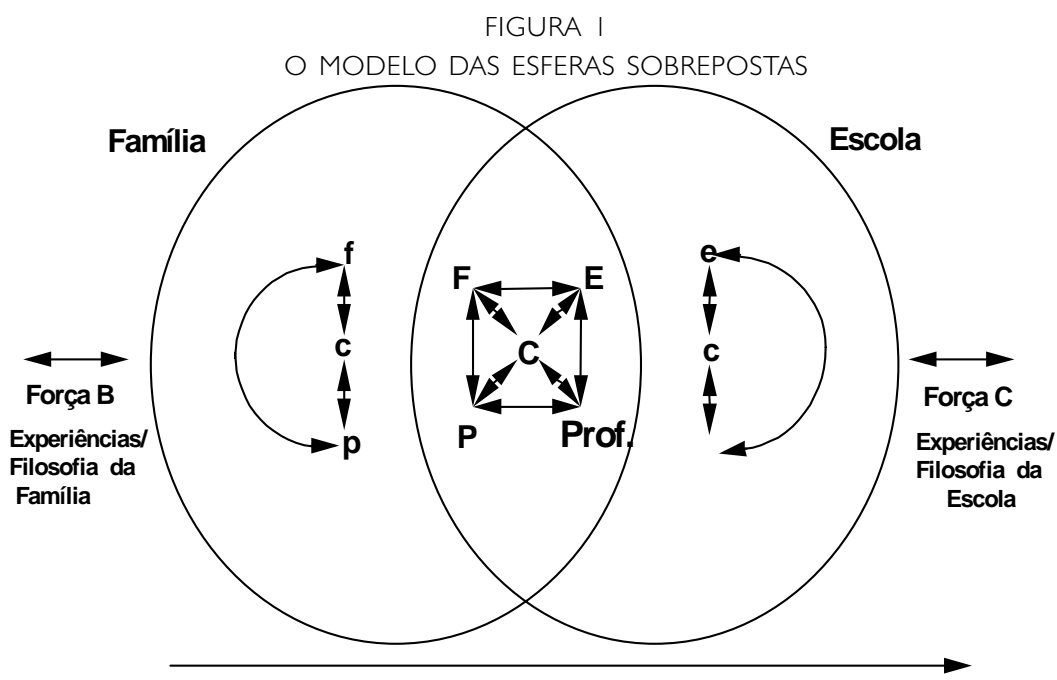

Força A --- Tempo / idade / série

Fonte: Epstein, Kaufmann, Losel (eds.), 1987.

Legenda: Interações intrainstitucionais (letras minúsculas)

Interações interinstitucionais (letras maiúscula)

F/f - família - E/e - escola - C/c - criança - P/P - pais - Prof./prof. - professor 
Apesar de haver diferenças distintas entre as obrigações da família e da escola, há também responsabilidades e objetivos comuns a ambas as instituições. Criar condições favoráveis para o desenvolvimento da criança é um dos objetivos comuns das duas instituições. Tanto uma quanto a outra influenciam e ajudam a determinar o curso da vida das crianças, razão pela qual a relação entre a escola e a família é vista como complementar e não como forças distintas e separadas. Partindo do princípio que reconhece o valor da relação escola-família, seja qual for a estrutura familiar, é possível pensar em como essa relação pode ser desenvolvida.

QUADRO I

CINCO TIPOS DE ENVOLVIMENTO DE PAIS

\section{CINCO TIPOS DE ENVOLVIMENTO DE PAIS}

Tipo no 1 - As obrigações básicas dos pais se referem às responsabilidades da família pela saúde, segurança e bem-estar da criança; à atenção às necessidades das crianças no seu processo de desenvolvimento e para o seu ingresso na escola; à criação de condições propícias para a aprendizagem escolar em casa; supervisão, disciplina e orientação.

Tipo $\mathbf{n}^{\mathbf{0}} \mathbf{2}$ - As obrigações básicas da escola se referem às responsabilidades da escola em enviar informações para os pais (ou responsável) sobre as regras e normas da escola, o seu funcionamento, os programas e métodos de ensino, o progresso das crianças e outras informações que sejam relevantes. As informações, mensagens, convites, boletins, e regras variam de escola para escola e em forma e freqüência.

Tipo no 3 - Envolvimento dos pais na escola se refere ao voluntarismo dos pais em ajudar os professores, orientadores e supervisores pedagógicos como também os administradores da escola, quer seja na escola em geral, quer seja na sala de aula, reuniões, eventos sociais, excursões ou outros como matérias extra-curriculares (arte e música) etc.

Tipo no 4 - Envolvimento dos pais em atividades feitas em casa que auxiliam a aprendizagem e rendimento escolar se refere à ajuda que os pais dão às crianças em casa, seja ela iniciativa dos pais ou dos professores (ou até mesmo das crianças) em atividades relacionadas com as atividades escolares, como deveres de casa, pesquisa, visitas a lugares culturais, etc.

Tipo no 5 - Envolvimento dos pais no governo da escola refere-se à inclusão dos pais no que diz respeito à tomada de decisões em geral, Associação de Pais, Colegiado, Conselho Administrativo; e ainda na intervenção junto às Secretarias e Ministérios. Este tipo também inclui movimentos da comunidade que afetam o trabalho da escola e das crianças.

Fonte: Brandt, 1989. p.25.

Muitos pesquisadores, na década passada, dedicaram seus estudos à identificação daquelas maneiras que os professores e as escolas estavam utilizando para trabalhar mais próximos dos pais e para que estes se sentissem atraídos para se envolver mais com a escola (Smith, 1980; Bastiani, 1986; Cyster et al, 1979; Wonfendale, 1983; Hannon, 1987; Epstein, 1982, 86; Jowett, 1988; 199| e outros). Ainda estes desenvolveram projetos que incluíam os pais no ensino da leitura e mais tarde da matemática que obtiveram resultados positivos não só para as crianças como também para os pais, que se sentiram mais "por dentro" do que se passava na escola (Hewison, Tizard, 1980; Tizard, Schofield, Hewison, 1982; Hannon, Jackson, 1987, Bryant, 1995 e outros). Epstein (1989), criou um tipologia de envolvimento de pais a partir de estudos que investigavam as maneiras usadas por professores em escolas americanas para incluir os pais no processo escolar em geral. Este modelo inclui cinco tipos 
que resumem as várias maneiras de termos os pais envolvidos com a escola (mais tarde, ela vem a adicionar um sexto tipo). Os cinco tipos são descritos separadamente, mas Epstein e Dauber ( | 99|) salientam que "esses cinco tipos não são puros, mas que envolvem aspectos comuns a todos os tipos e que a maioria das maneiras até então encontradas se encaixa em um dos cinco tipos" (p. 29l).

Essa tipologia, de acordo com Epstein (1989), geralmente ocorre em lugares diferentes, precisam de materiais diferentes e conduzem a resultados também diferentes e distintos.

O sexto tipo foi incluído mais tarde por recomendação do California State Board of Education, em 1988 (Epstein e Dauber, 1991), classificado da seguinte forma:

Tipo n ${ }^{\circ} 6$ - Colaboração e trocas entre as escolas e organizações das comunidades que se refere àqueles programas escolares que permitem aos pais e às crianças (e aos seus profissionais) o acesso aos serviços prestados por aquelas instituições que estão direta ou indiretamente relacionados com o bem-estar das crianças, sua segurança, saúde e oportunidades futuras (serviço social e da saúde, instituições culturais e religiosas, como museus, bibliotecas, zoológicos, e igrejas, que colaboram e enriquecem a educação das crianças (e das famílias). As escolas também variam muito no quanto eles sabem a respeito dessas facilidades e no tanto que fazem uso das mesmas.

Epstein e Dauber ( 1991 ) ressaltam que esta tipologia é sempre muito útil para todos os profissionais ligados à educação que pretendem passar ou já estão passando pelo processo de implementação de programas para o envolvimento de pais. Esta tipologia é também muito importante no processo de identificação dos tipos que nos auxiliarão a responder às necessidades dos pais, professores e crianças. E principalmente, quando não estamos tão familiarizados com a vasta gama de opções que há para o envolvimento adequado e ajustado a cada situação particular dos pais com a escola, professores e o ensino/aprendizagem. Epstein e Dauber (|99|) ainda acrescentam:

[...] aquelas escolas que incluem os cinco tipos de envolvimento ajudam os pais a criarem um ambiente em casa mais propício e convidativo à aprendizagem e para os estudos; a entenderem melhor as mensagens vindas da escola; a se tornarem parceiros da escola de uma maneira mais produtiva; a dividirem as responsabilidades com a escola criando oportunidades em casa que auxiliem a aprendizagem escolar com atividades relacionadas com o curriculum para além dos deveres de casa; e as escolas levam em consideração as opiniões dos pais em decisões que afetam o bom funcionamento da escola e as crianças. (p. 29|-2)

A utilização de um modelo já existente e que já foi usado e aplicado inúmeras vezes em várias escolas é sempre muito prático, vantajoso e mais econômico. Isto é verdadeiro desde que o contexto econômico-sociocultural em que a escola está inserida não seja uma questão relevante. Como já foi mencionado, o modelo que Epstein criou tem continuamente ajudado escolas (de $1^{\circ}$ e $2^{\circ}$ graus), de todos os níveis sociais, a desenvolver programas que 
auxiliam a implementação de tais programas e a manutenção de uma relação produtiva, satisfatória e saudável entre os pais e professores. Essa tipologia pode ser também útil para escolas em outros países em contextos semelhantes aos das escolas americanas (como as de alguns países europeus). No entanto, e como já verificamos em outras áreas, a importação de determinados modelos para a nossa realidade brasileira necessita sempre de mudanças e reformulações para que se obtenha melhores resultados e que se verifique um crescimento apropriado. Modelos importados muitas vezes não prevêem problemas e situações que são característicos da sociedade brasileira. No entanto, o modelo americano pode servir de base para uma possível avaliação do que se passa em nossas escolas sobre a relação escola-família e professores/pais, o que as partes interessadas pensam a respeito do tópico e ainda identificar práticas já existentes, uma vez que, de uma forma ou de outra, sabemos que nas escolas brasileiras há sempre o contato com os pais, porém, em formas e freqüências que, muitas vezes, deixam a desejar.

Ao investigar a posição dos pais em outros contextos (como o americano e o europeu), alguns fatos comuns foram detectados indiferentemente de raça, nacionalidade ou posição social, profissional e econômica: a maioria dos pais ajudam os filhos, direta ou indiretamente, nos deveres de casa ou em outras atividades escolares e quando não os ajudam é sempre por motivos maiores, como um desequilíbrio sério de diversas ordens; todos os pais querem ver seus filhos vencerem academicamente, não querem que eles abandonem a escola antes do tempo previsto e vêem nela a possibilidade de um futuro melhor para seus filhos (Zanelle et al. 1997). Carvalho (1989), ao relatar sobre os problemas surgidos pelo isolamento do sistema público de ensino em relação aos movimentos organizados, às expectativas e mesmo à vida cotidiana da população, menciona o trabalho de Campos no qual é ressaltado o grande interesse da população das camadas populares na escola e a revolta da população com o fechamento a suas tentativas de participação. Estudos brasileiros (Carvalho, 1989; Vianna, 1993) nesse campo destacam, principalmente, o movimento das camadas populares em luta pela escola, pelo acesso e melhoria da qualidade do ensino público e sobre a relação creche-famíla (Haddad, 1987). Geralmente, nossos estudos enfatizam o envolvimento de mães e a luta por mais acesso à escola e por uma educação pública melhor, porém sem maiores envolvimento com o ensino e aprendizagem como o modelo de Epstein sugere. A luta geralmente passa por níveis estruturais representados por associações de pais e mestres, colegiados e conselhos de escola, nos quais percebe-se a participação absoluta de mães. Entretanto, Zanella et al. (1997) defende que a "participação dos pais significa visualizar a escola como um espaço democrático em que as pessoas podem exercer a sua cidadania" (p. I 45) e, portanto, os pais deveriam ter a possibilidade de se envolverem com o "processo ensino-aprendizagem, e ter o espaço à voz, à vez e ao voto" (p. I45).

Outro ponto importante mencionado pelos pais é o fato de a maioria deles estar disposta a contribuir de alguma forma para a escola, ou seja, desde aprender a criar um ambiente mais saudável em casa para que os filhos se sintam mais motivados para as ativida- 
des escolares, até prestar ajuda dentro e fora da sala de aula. Porém, nós sabemos que a grande maioria dos pais precisa de instruções sobre como, quando e o quê fazer para colaborar neste processo. Para isso, é preciso que a escola também faça a sua parte de maneira que a "divisão das responsabilidades" seja balanceada e justa, sem a negação das responsabilidades de cada um.

Esses estudos também nos dizem que os professores, quando fazem parte de programas de envolvimento de pais, reconhecem-lhes a importância e o valor de sua ajuda em todos os sentidos, desde a ajuda prestada em casa até àquela prestada na escola. Epstein e Dauber (199|) concluíram que, quando os professores incluem os pais na sua rotina de trabalho, esses pais começam a interagir mais com as crianças em casa, sentem-se mais confiantes em ajudá-los, acham que os professores são melhores, mais competentes e confiantes no que fazem e, por outro lado, as crianças começam a melhorar em comportamento e rendimento. Bastiani ( 1993 ) concluiu que, por essas razões, temos de aceitar que já não é mais possível dar a volta, temos de apoiar essa relação e admitir que ela é imprescindível.

Este estudo pretende examinar a opinião dos pais (que no caso foi representada por maioria absoluta de mães e uma avó) no que diz respeito a outras maneiras de envolvimento de pais na escola. Nós acreditamos que os pais brasileiros também participam ativamente do processo escolar, seja de forma direta ou indireta, consciente ou não, certa ou errada (dentro do que é esperado que a criança faça), de que estão fazendo alguma coisa relacionada com a aprendizagem escolar; que também querem ver seus filhos bem-sucedidos na escola; que também querem um futuro melhor para seus filhos, mas que talvez não o façam da maneira sugerida por Epstein em sua tipologia.

\section{METODOLOGIA}

\section{A amostra}

Vinte mães e uma avó de crianças de $4^{a}$ série (doze meninos e nove meninas) do $1^{\circ}$ grau foram selecionados em oito escolas estaduais situadas na zona sul de Belo Horizonte, Minas Gegais. Os pais (não determinamos previamente que seriam só mães) foram selecionados de acordo com o aproveitamento escolar das crianças — acima da média, na média e abaixo da média; a capacidade dos pais de manterem um diálogo simples com a entrevistadora (não especificamos a camada social); e que fossem pais de crianças da $4^{a}$ série. Como o número de entrevistas tinha que ser limitado, nós utilizamos esse critério de seleção para que tivéssemos uma amostra variada e a mais representativa possível da comunidade de pais que tem os filhos naquelas escolas estaduais. Apesar de não termos especificado qual dos pais nós gostaríamos de entrevistar, as entrevistas foram feitas sempre com as mães e com uma tutora legal (que era a avó da criança) e em somente duas situações os pais estavam presentes. Nas duas situações, em que ambos os pais estiveram presentes, pedimos que colaborassem ex- 
pressando suas opiniões. É interessante notar que a nossa amostra ainda reflete o padrão tradicional no qual as mães são as responsáveis pela orientação das crianças, quando se trata de assuntos da escola. No caso das mães divorciadas e solteiras, a entrevista foi feita com elas pelo fato de terem a guarda legal da criança e, portanto, a escola já nos reportou a elas e não aos pais.

Os Quadros 2 e 3 nos mostram a escolaridade e o grupo de idades das entrevistadas:

QUADRO 2

ESCOLARIDADE DAS MÃES

\begin{tabular}{|l|c|c|}
\hline & Número & Porcentagem \\
\hline $1^{\circ}$ grau incompleto & 1 & 4,8 \\
\hline $1^{\circ}$ grau completo & 6 & 28,6 \\
\hline $2^{\circ}$ grau completo & 9 & 42,9 \\
\hline Grau superior & 5 & 23,8 \\
\hline Total & 21 & 100,0 \\
\hline
\end{tabular}

QUADRO 3 GRUPOS ETÁRIOS DAS MÃES

\begin{tabular}{|l|c|c|}
\hline & Nímero & Porcentagem \\
\hline $30-39$ & 13 & 61,9 \\
\hline $40-49$ & 7 & 33,3 \\
\hline 50 e mais & 1 & 4,8 \\
\hline Total & 21 & 100,0 \\
\hline
\end{tabular}

Das mães entrevistadas, 75\% estavam empregadas e 20\% delas estavam em casa, e, em um caso, a mãe já estava aposentada e cursava o magistério, pois tinha como ideal vir a ser professora primária. Entre os pais, havia dois aposentados e em casa, dois desempregados, e os outros se encontravam empregados ou com negócio próprio. O grupo consistia de uma mãe solteira, 5 mães divorciadas, uma avó tutora legal da criança, e 14 casadas.

Apesar do pequeno tamanho do grupo, a amostra apresentou uma mistura bem variada em termos de habilitações acadêmicas, funções profissionais, local de residência e grupo social. Todos contribuíram com suas expêriencias de vida, como pais e cidadãos no que diz respeito à educação de seus filhos. Todos os pais discursaram a respeito das razões que os levaram a colocar seus filhos em escolas estaduais e das outras opções existente no mercado. Manifestaram também suas opiniões sobre o tópico que dizia respeito a suas próprias vidas e estórias, e também como percebiam a situação das escolas e de seus filhos.

grupo de crianças foi também variado em termos de rendimento escolar e foi classificado pelos pais de acordo com o Quadro 4:

QUADRO 4

RENDIMENTO ESCOLAR

\begin{tabular}{|l|c|c|}
\hline & $\begin{array}{l}\text { Número de } \\
\text { Crianças }\end{array}$ & Porcentagem \\
\hline Abaixo da média & 5 & 23,8 \\
\hline Na média & 6 & 28,6 \\
\hline Acima da média & 10 & 47,6 \\
\hline Total & 21 & 100,0 \\
\hline
\end{tabular}

Até 49\% - abaixo da média; 50 a 69\% - na média;

70 a 100\% - acima da média. 
Nós também consideramos, ao selecionar o grupo de pais de crianças de $4^{\text {a }}$ série, os resultados de pesquisas que indicam que a relação entre pais e escola muda de acordo com o nível em que a criança está (os pais de crianças nas primeiras séries do $l^{\circ}$ grau tendem a ser mais participativos, resultados esses confirmados por Zanella ( 1997) para o Brasil), a idade da criança, o grau de dificuldade/facilidade e a adaptação na escola. Concluímos então que os pais de crianças de $4^{a}$ série já teriam passado por experiências variadas ao longo dos anos em que seus filhos vêm frequentando a escola primária, não só em relação ao envolvimento de pais com a escola, mas também em outros aspectos que tenham implicações importantes para a relação escola-família.

\section{A ENTREVISTA}

O questionário usado para as entrevistas consistia em duas partes: a primeira apresentava quarenta afirmações sobre as diferentes formas de envolver os pais com a escola, tiradas de um questionário elaborado por Epstein (maneiras que se encaixam nas cinco categorias da tipologia de Esptein), e ainda de outras pesquisas realizadas em outros países (Cyster, Clift, Battle, 1979; Jowett, Baginsky, 1988; Jowett, Baginsky, MacNeil, 1991; Stacey, 1991, e outros). Os respondentes tinham de indicar o grau de importância, numa escala de um (sem importância nenhuma) a sete (muito importante), que delegariam a cada uma das afirmações. Esta parte foi incluída no questionário com dois objetivos:

a.propositadamente para dar conhecimento aos pais das diversas maneiras que eles poderiam se envolver com a escola, principalmente caso eles ainda não estivessem familiarizados com o tópico, e como uma preparação para a segunda parte do mesmo;

b. para que esses dados fossem colocados em contraste com os dos professores das mesmas escolas, que mais tarde serão analisados.

Em todas as duas partes, os pais (lembre-se que dois pais estiveram presentes na entrevista) podiam fazer comentários, perguntas, dar exemplos, fazer sugestões e voltar a questões anteriores. Foi adotada, portanto, uma postura bastante flexível na condução da entrevista, mas, em todos os casos, foi seguido o planejamento inicial da ordem das questões. Burgess ( 1984) defende que os pesquisadores não devem aplicar seus métodos rigidamente quando pretendem coletar dados qualitativos, mas sim que sejamos flexíveis na maneira como conduzimos a entrevista.

Foi então feita uma análise qualitativa dos dados. Os resultados nos mostram como esse grupo percebe a relação escola-família, professores/pais e o envolvimento deles com o processo escolar de seus filhos. Dado o número de entrevistas, a análise foi feita considerando o ponto de vista do grupo como um todo com todas as suas diferenças e nuanças. 


\section{RESULTADOS E DISCUSSÃO}

As opiniões variavam desde não tendo interesse nenhum em se envolverem com a escola ou com o processo de ensino/aprendizagem até contribuir com todos os aspectos que a escola precisar ou pedir (como ajudar nas festividades; arranjar fundos para aquisição de material — livros, vídeos, televisão, material didático, instrumentos para um laboratório de ciências - e ainda outros recursos que auxiliem o ensino; auxílio na reparação do espaço físico; preparação para reuniões e encontros, etc).

Joyce Epstein (1990), ao desenvolver a sua teoria das esferas sobrepostas, descreve duas filosofias opostas sobre a relação escola-família:

a. a primeira enfatiza uma incompatibilidade inerente, uma competição e um conflito entre a escola e a família. Esta primeira categoria apóia a idéia de que as duas instituições - escola e família — são e devem ser regidas pelos profissionais da educação e pelos pais respectivamente e separadamente. Eles, os profissionais e os pais, só poderão alcançar seus objetivos se fizerem o seu papel assumindo suas responsabilidades independentemente um do outro. Isto é, afirma-se que os objetivos de cada instituição — escola e família — são alcançados mais eficientemente quando os professores cumprem os seus deveres dentro do seu próprio espaço - a escola e sala de aula; e os pais por sua vez cumprem o seus deveres e o seu papel, mantendo as suas opiniões e críticas, dentro do seu próprio espaço - o seu lar (Parsons, Waller, Weber apud Epstein, 1990).

Apesar de esta primeira filosofia parecer muito antiga para o nosso momento, alguns pais sugeriram que o trabalho dos professores deve ser desenvolvido sem a interferência deles, tanto na rotina diária como em outros aspectos da educação (dentro e fora da sala de aula). Alguns deles, mesmo os que têm o nível de escolaridade mais alto, como os graduados, indicaram que não gostariam de estar envolvidos com a escola em nenhum aspecto e, principalmente, no que diz respeito ao processo de ensino/aprendizagem. Para além disso, manifestaram também, e, já neste caso, a grande maioria deles, um certo desinteresse em se envolver com a educação escolar, pelo simples fato de acreditarem que não estão dando a oportunidade para os filhos se tornar independentes. Acreditam que a escola oferece às crianças a oportunidade de se tornarem gradativamente mais independentes, mais confiantes na própria capacidade e, conseqüentemente, mais maduros. Com a participação mais ativa dos pais, eles acreditam que esse processo seria retardado. Esse aspecto tem sido muito pouco encontrado em pesquisas anteriores, pois o envolvimento de pais com a educação não pretende ser uma estratégia de ajuda em que se faz ou executa-se uma atividade/tarefa para as crianças, mas uma maneira de maximizar as oportunidades para ela — tanto em casa quanto na escola. $\bigcirc$ objetivo é uma educação voltada para a capacidade da crian- 
ça, na qual ela aprende pela exploração e pesquisa executando as tarefas com o máximo de interesse, interação e aproveitamento. $\bigcirc$ processo de envolvimento dos pais promove, para ambas as partes, o conhecimento dos ambientes nos quais as crianças freqüentam e, conseqüentemente, desencadeia uma conscientização dos objetivos da educação escolar e familiar que finalmente levará a uma atitude de congruência e harmonia com a escola e a vida familiar.

b.por um outro lado, a segunda perspectiva enfatiza a coordenação, cooperação e a natureza complementar da escola e da família, e apóia a colaboração entre as duas instituições. Defende também que, para haver uma colaboração entre elas, é preciso desenvolver uma comunicação mais freqüente e mais informativa entre as duas partes. Esta filosofia parte do princípio que as escolas e as famílias devem dividir suas responsabilidades no que diz respeito à educação e socialização da criança. Professores e pais têm, portanto, objetivos comuns, e eles serão mais facilmente alcançados quando ambas as partes se fizerem conhecer e aos seus objetivos. Esta perspectiva é baseada no modelo de interações inter-institucionais e na abordagem ecológica (Bronfenbrenner, Leichter, Litwak, Meyer apud Epstein, 1990) que apontam para as conexões necessárias entre indivíduos e seus grupos e organizações para um desenvolvimento progressivo e adequado.

Alguns pais (30\% do grupo) manifestaram o interesse em se envolverem com a escola, com o processo ensino/aprendizagem e ainda se mostraram disponíveis para uma possível oportunidade em ajudar a escola com a preparação para as aulas como, por exemplo, a instalação de um laboratório simples e barato para as aulas de ciências se tornarem mais interessantes e ainda outros equipamentos, caso a escola estivesse aberta para este tipo de intervenção dos pais. A intensidade com que os pais (agora em uma porcentagem maior) se mostraram interessados em se envolverem com a escola em geral variou: alguns queriam entender mais sobre o trabalho dela, dos professores, seus métodos de ensino, disciplina, orientação dentro e fora da sala de aula, bem como em matérias diferentes, sobre as relações criança-criança, criança-professor(es); outros só queriam participar de eventos que não estivessem ligados a assuntos de sala de aula, mas ainda apreciariam se a escola os informasse mais claramente sobre o que se passa lá dentro.

O que é interessante notar é que os pais brasileiros, como os pais de outros países e realidades, também querem um acesso maior à informação, um diálogo mais aberto com os professores e uma confiança maior naquilo que a escola faz para preparar as crianças para um futuro melhor.

Independentemente do grau de envolvimento propiciado pela escola e família nesta amostra, podemos afirmar que as mães e a tutora entrevistadas querem que seus filhos terminem o $2^{\circ}$ grau, que sejam bem-sucedidos social e profissionalmente, tanto ou mais do que elas. 


\section{AS ILHAS E SEUS NAVIOS: A DINÂMICA DE SUAS TROCAS E NEGÓCIOS}

As entrevistadas expressaram suas opiniões a respeito dos quatro maiores componentes dessa relação; escola, professores, crianças e pais. A relação entre eles, vista por esse grupo, poderia ser representada metaforicamente, como um grupo de ilhas que criou um sistema de transporte (barcos e navios) para a importação e exportação daqueles produtos necessários para seu próprio desenvolvimento. Para continuarem a crescer de uma forma constante e estável, foi preciso que essas ilhas criassem um sistema de trabalho que funcionasse bem e que, principalmente, atendesse às necessidades de todos.

As ilhas — as escolas e seus membros — a casa — família e seus membros — precisam umas das outras para serem produtivas e eficientes; os navios e barcos - a comunicação, a ajuda, e o envolvimento (as três categorias que os pais usaram para falar a respeito de suas experiências com a escola de seus filhos) - executam o processo de importação e exportação criado pelas ilhas. As cargas destes navios e barcos representam todas aquelas iniciativas, tentativas e oportunidades para a implementação das maneiras pelas quais vão ser assimiladas as ajudas e envolvimento dos pais e vice-versa. As cargas são, portanto, todas as formas de comunicação desenvolvidas pela escola e pelos pais. Incluem também o estilo e método de ensino, a aprendizagem, o comportamento e cultura das partes envolvidas, e a força de trabalho. As negociações, isto é, as maneiras como os pais e professores lidam uns com os outros, determinam a natureza das relações, e o uso dos produtos importados determina a assimilação do que é proposto por ambas as partes.

Como na vida real, os navios precisam de uma determinada estrutura em "terra firme". É preciso, portanto, que cada ilha se prepare adequadamente para entrar nesse sistema de trocas e negociações e que tenha condições de receber os navios e os enviar para outros destinos. É sempre possível que problemas ocorram e que muitas vezes impeçam o desenvolvimento natural das negociações. As negociações geralmente implicam o envolvimento de vários profissionais de todos os níveis de especialização para o bom funcionamento e bons resultados.

De forma muito semelhante, o mesmo ocorre no "sistema" de envolvimento de pais: teremos uma variação enorme em termos de habilitações profissionais, classes sociais, demandas, necessidades, e recursos. Por exemplo, uma forma de contato muito comum usada em todas as escolas são as circulares, reuniões e mensagens (a última sendo também enviada pelos pais para a escola). $\bigcirc$ conteúdo desses contatos nem sempre é "assimilado" por todos da maneira esperada. Isto pode atrasar ou mesmo impedir que a relação escolafamília se mova de algum lugar para outro mais produtivo. De volta à metáfora, as cargas ficam muitas vezes inutilizadas e, portanto, perdidas e sem destino. Em muitos casos, ela atinge seu destino final, mas fica encostada num depósito sem ser processada e usada. Por exemplo, quando os pais oferecem serviços que tem implicações curriculares (ex. o labora- 
tório de ciências), mas os professores (ou outro funcionário da escola) não assimilam a idéia como uma contribuição valiosa, a oportunidade passa e aquele momento é perdido. Ou quando a escola fornece informações que não são assimiladas pelos pais (ex. uso de jargões quando explicam seus métodos de ensino e funcionamento da escola), que continuam a pensar da mesma maneira sobre a escola.

É preciso realçar aqui que o envolvimento dos pais com a escola e a educação escolar é um processo (projeto) que se desenvolve à medida que as necessidades vão sendo identificadas e as pessoas envolvidas vão se aproximando e se conhecendo mais. Este processo-projeto tem, basicamente, um caráter flexível e móvel. Anda sempre em direção à necessidade de todas as partes envolvidas, e, principalmente, em favor das crianças.

Como em qualquer outra instituição, a escola constrói a sua cultura baseada nas contribuiç̧ões de todos, mas, principalmente, com as contribuiç̧ões vindas de casa, com as crianças. É preciso então que a escola e os pais se relacionem mais claramente e que as "negociações" sejam feitas de modo a suprir ambos os lados satisfatoriamente. Aqui o elemento básico é a comunicação. Todas as outras formas de envolvimento de pais se apóiam nos meios usados para se fazerem entender um ao outro. Epstein, Connors (1992) defendem que, como os sócios em uma empresa ou empreendimento, os "sócios" na educação devem procurar entender claramente quais são os interesses e responsabilidades comuns às duas instituições sobre a educação das crianças pelas quais ambos são responsáveis. Eles ainda acrescentam que os sócios devem procurar desenvolver a confiança uns nos outros, organizar suas responsabilidades, perceber a posição de cada um e, acima de tudo, respeitar as contribuições, investimentos e possibilidades da outra parte.

Epstein e Dauber (199|) mostram-nos que as "sociedades" (partnership) que têm laços fortes se desenvolvem à medida que os interessados trocam informações e idéias; trabalham juntos principalmente na avaliação dos resultados e revendo as necessidades; estabelecem objetivos comuns (e realistas), planejam e implementam projetos; comemoram os resultados (sucessos) e revêem as atividades que vão auxiliar o desenvolvimento das crianças. Epstein e Dauber afirmam que interações mais abertas e programadas entre os professores e os pais resultam em melhores escolas, famílias, assim como programas para a comunidade.

A característica principal do processo de envolvimento de pais é a constante avaliação e revisão dos projetos para que possamos ir ao encontro do público que servimos e garantir a compreensão das "negociações" e o bem-estar das crianças. O ponto de partida é o conhecimento dos nossos objetivos na qualidade de escola e de pais.

\section{AS ESFERAS SOBREPOSTAS E O SISTEMA DE TRANSPORTE: MODELOS DA RELAÇÃO ESCOLA-FAMÍLIA}

As esferas sobrepostas também movimentam-se para frente e para trás de acordo com as necessidades, demandas, experiências e filosofias das duas instituições. As duas esferas 
estão constantemente sob a força C - tempo, nível de escolaridade e idade da criança. As duas esferas representam duas instituições muito complexas. Seus elementos - pais, crianças, professores (supervisores, orientadores, diretores), escolas - têm estilos e culturas diferentes. As culturas das duas esferas ajudam a determinar o grau de sobreposição das esferas.

No nosso "sistema de transporte", os elementos são as ilhas, os navios e as cargas. Essa nova organização nos permite ver a relação de maneira mais prática e realista. Nosso modelo retrata a dinâmica da relação em um sistema ativo e simultâneo de trocas e negociações. Estende ainda a detalhes que nos mostram a complexidade da relação, com suas dificuldades operacionais. As "forças" são o volume e a intensidade das negociações (o número de pais varia, assim como suas necessidades, demandas e capacidade para ajudas e envolvimento). A comunicação toma um lugar central no sistema das ilhas. $\bigcirc$ nosso modelo ilustra o lado operacional da relação, enquanto as esferas sobrepostas nos fornecem o modelo teórico no qual a relação escola-pais se baseia.

\section{COMUNICAÇÃO, ENVOLVIMENTO E AJUDA}

As entrevistadas colocaram suas opiniões dentro das seguintes categorias: comunicação, ajuda, e envolvimento (ver Figura 2). Apesar de serem categorias distintas, notou-se que a comunicação tem um papel maior e abrange aspectos das outras duas categorias.

\section{ENVOLVIMENTO}

A grande maioria do grupo colocou a categoria "envolvimento" como uma forma de participarem mais intensamente de atividades que estão relacionadas ao ensino e à aprendizagem escolar, em casa ou na escola (sala de aula). Estas atividades podem também ser iniciadas pelos próprios pais em casa, ou sugeridas pelos professores. Elas são bem abrangentes e tratam dos diversos procedimentos adotados pelos pais para auxiliar os filhos na aprendizagem, como, por exemplo, deveres de casa, leituras de livros que interessam aos pais e às crianças, jogos que estimulam o desenvolvimento cognitivo, etc, até a participação ativa dos pais na escola. Além dessas atividades desenvolvidas em casa, mencionaram a ajuda em sala de aula ou no uso da biblioteca, excursões a lugares culturais e outras atividades que os professores quisessem ou precisassem da participação deles (como falar das diferentes profissões). Ainda mais, alguns mencionaram sua participação na preparação de ambiente para as aulas, como a montagem de um laboratório simples para as aulas de ciências naturais, para educação física, revisão de textos e livros que serão usados em aula e destinados à biblioteca.

Esta categoria foi fortemente relacionada com as atividades intelectuais que requerem dos pais uma preparação, uma orientação constante vinda dos professores e ainda uma avaliação periódica das atividades e do processo de execução dessas. 
A grande maioria das entrevistadas neste grupo, não soube identificar maneiras que as levariam a uma participação mais ativa do processo escolar, mesmo depois de ter respondido à primeira parte do questionário. Por exemplo, a idéia de ajudar os professores com o ensino, mesmo sendo a ajuda significativamente pequena (como simplesmente ler um livro com o filho ou escutá-lo ao ler em voz alta) foi considerada como remota, pois sequer haviam pensado em fazer coisas do tipo. Além de não se verem fazendo atividades relacionadas com o ensino/aprendizagem, pensam que isto não seria possível por várias razões, tanto por suas próprias capacidades, quanto por forças maiores (tempo, diferença de horários, etc).

FIGURA 2

O SISTEMA DE TRANSPORTE

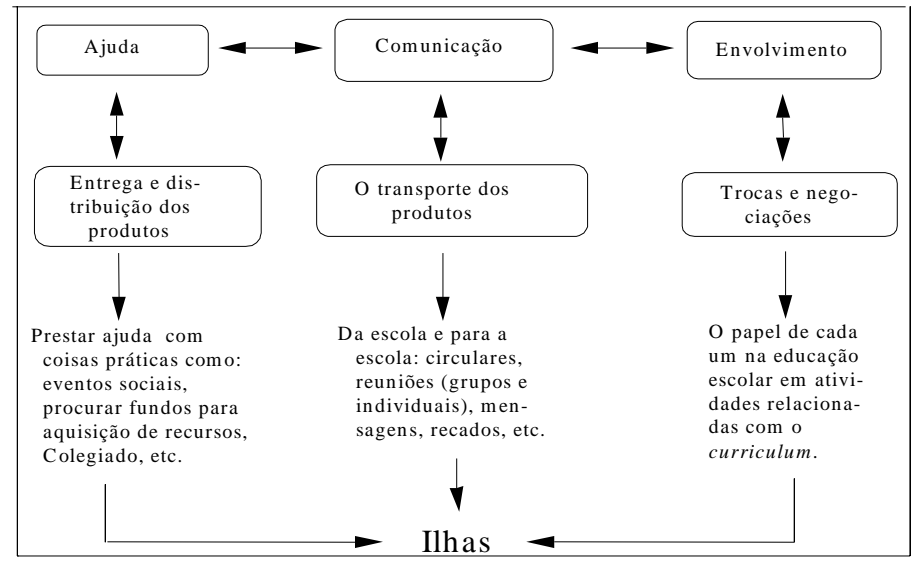

Esta categoria — envolvimento — assim como ela foi descrita, pode ser dividida em duas subcategorias: a) não querem/podem se envolver com o ensino e a aprendizagem; b) gostariam de participar mais ativamente das atividades escolares em geral. Ainda uma terceira subcategoria, porém com um pouco menos de força, é formada por aquelas que não vêem o quê nem como poderiam contribuir para todo o processo escolar de seus filhos; não conseguem visualizar essa união entre os professores e os pais. É preciso ressaltar aqui que não se espera que todos os pais em uma mesma escola se envolvam da mesma forma e na mesma intensidade, mas sim que haja uma compreensão, numa curva crescente, sobre o processo ensino/aprendizagem e os objetivos da escola.

a. Entre as que não querem o "envolvimento", a maioria afirmou que preferiam se comprometer com outros aspectos escolares que não fossem aqueles relacionados com o ensino, o curriculum ou a aprendizagem. Indiferentemente de sua posição socioeconômica e cultural, muitas (73\%) mencionaram quais os papéis da escola e da família. Acreditam que o bem-estar geral das crianças é antes de 
tudo responsabilidade dos pais ao passo que é obrigação da escola preparar as crianças intelectualmente. Uma das mães coloca assim: "Eu não acho que eu poderia fazer o que a escola faz, que é ensinar na sala de aula...eu devo fazer outras coisas... coisas que os pais devem fazer, tomar conta dos meninos, isso sim." (mãe n. 16, escola n 6).

Todo o grupo entrevistado, sem exceção, mostrou-se preocupado com a qualidade do ensino, com a capacidade da professora, com sua sensibilidade para perceber os meninos e conhecê-los, assim como em saber se a escola estava fazendo alguma coisa para melhorar o ensino e seus recursos (tanto material quanto humano). As entrevistadas delegavam essa responsabilidade aos professores, orientadores e supervisores pedagógicos e diretoras, e não imaginavam o que poderiam fazer para modificar a situação, caso não estivessem satisfeitos. As razões dadas para justificar essa posição iam desde o medo de não saber ajudar os filhos da maneira esperada e correta (essa foi uma razão bastante mencionada até mesmo por aquelas que queriam o "envolvimento" de maneira mais profunda), e de ter de admitir aos outros que não sabem fazer determinadas tarefas, até o fato de não estarem interessadas porque acham que isso é tarefa da escola, e que ela deve fazê-lo bem e sem "incomodar" os pais; ou pelo simples fato de não terem um tempo disponível, pois trabalham horário integral e as vezes até mais do que isso.

b. Aqueles que querem o "envolvimento": I/3 do grupo manifestou interesse em se envolver com questões e atividades relacionadas com o ensino/aprendizagem, tanto em casa como na escola. Algumas entrevistadas já avançaram nesta direção por iniciativa própria e não da escola. Nenhuma das entrevistadas estava a par de alguma iniciativa das escolas, mesmo que estas fossem informais ou em nível individual, no sentido de as informar a respeito do processo ensino/aprendizagem, do curriculum ou objetivos gerais da escola.

A informação exerce um papel crucial nesse processo de envolvimento dos pais. Epstein ( 1 986) e Tizard, Mortimore, Burchell ( 198 I) concluíram que, quando as escolas não fornecem aos pais informações sobre seus objetivos e como eles pretendem alcançá-lo, eles tendem a julgar que a instituição não está interessada em ter os pais por perto. Conseqüentemente, afastam-se, tomando uma postura defensiva. Além disso, tendem a agir negativamente em relação ao que a escola faz e prejulgam a capacidade dos professores.

A categoria $b$ - pais que gostariam de participar mais ativamente das atividades escolares - vem nos mostrar que há pais que se interessam pelo envolvimento, levando-nos a pensar que a escola deveria fazer bom proveito desse recurso extra. Este resultado confirma aqueles encontrados em pesquisas de outros países e revela que essa categoria é uma possibilidade viável também na realidade brasileira.

Dauber e Epstein (1989) e Epstein (1986) sustentam que, quando os professores se compremetem a trabalhar para ajudar os pais a compreenderem o trabalho da escola, os 
pais, indiferentemente do background pessoal, conseguem ser mais produtivos no que diz respeito ao seu envolvimento na educação dos filhos. Eles também defendem que a atitude dos professores, somadas às maneiras desenvolvidas para manterem contato com os pais, são variáveis muito importantes, que determinam como eles vão se tornando mais informados, ativos e participativos, tanto na relação escola-família como no processo escolar.'

Um grupo expressou também uma grande insatisfação pela maneira como a escola os guiava e informava sobre o desenvolvimento e progresso de seus filhos. Estes são pais de crianças que apresentavam dificuldades de aprendizagem, baixo rendimento e grande desinteresse pela escola. Estavam dispostos a dedicar grande parte do seu tempo disponível para ajudar seus filhos com as atividades escolares, e, acima de tudo, compreender melhor o problema e a dificuldade que os filhos vêm enfrentando desde a entrada na instituição. Queriam principalmente evitar o fracasso escolar e, para tanto, gostariam de contar com a ajuda da escola e de seus profissionais, no sentido de orientá-los e induzi-los a agirem mais adequadamente. Gostariam que a escola os informasse sobre os recursos existentes para ajudar tais alunos ou outros recursos, mesmo que fora da escola, mas que os ajudariam no acompanhamento dos filhos.

Esta categoria depende muito da "política" da escola em estabelecer vínculos com os pais (e com outros profissionais direta/indiretamente relacionados com a educação escolar) para que se possa obter resultados positivos e construtivos. Geralmente os pais, não só os que participaram deste estudo - na realidade vinte mães e uma avó -, mas em toda nossa realidade brasileira, precisam de alguma forma de preparação, informação e ajuda para que se sintam parte do processo escolar, do desenvolvimento dos filhos e compreendam o sistema e o funcionamento, o ensino/aprendizagem, e a dinâmica da escola.

\section{AJUDA}

"Ajuda" (colaboração) foi a palavra mais usada pelo grupo para definir seu papel em relação à educação escolar de seus filhos. "Ajuda" esteve sempre relacionada com prestação de serviços, por exemplo, em eventos sociais, feiras, esportes, excursões e outros. Outra maneira de ajudar a escola que este grupo mencionou estava relacionada com a aquisição de materiais e equipamentos para a escola (como a aquisição de uma máquina de xerox para uma das escolas, que foi iniciativa dos pais). As mães, principalmente aquelas que fazem parte do colegiado (neste estudo, eram quatro), vêem a relação escola-família como uma possibilidade de aliviar os professores de determinados trabalhos que poderiam ser feitos por outras pessoas para que eles possam se dedicar somente ao ensino, às crianças, à preparação das

I. Queremos enfatizar que o objetivo de envolver os pais com a escola não é fazê-los concordar passivamente com todas as suas regras, mas sim basear a relação em trocas e "negociações" que sejam satisfatórias para ambos os lados e, principalmente, que facilitem o sucesso escolar. 
aulas e correção de testes, exercícios de casa, pesquisas, textos, etc. Uma mãe mencionou, por exemplo, que as contratações de professores para a Educação Física e Artes estavam ameaçadas e os professores sentiam-se muito frustrados por não ter condições de lutar contra isso junto à Secretaria do Estado. Os pais do colegiado uniram-se a outros para assumir a luta. Naquele momento, ainda estavam em negociações com a Secretaria. Apesar de, na maioria das vezes, as que eram membros do colegiado serem mais ativas no "prestar ajuda" à escola, as outras manifestaram que se sentiriam mais à vontade e confiantes em colaborar com coisas práticas do que com aquilo que exigiria um esforço intelectual maior, e mais tempo de preparação. Estas já haviam feito coisas desse tipo no passado, a pedido da escola.

Ajuda e colaboração (como foi definido pelo grupo entrevistado) vinda da comunidade em geral é sempre bem-vinda nas nossas escolas estaduais. É preciso, no entanto, que haja o mínimo de organização e informação para que esta ajuda seja produtivamente incorporada pelas escolas e reconhecida pelos pais (e outros). Esta categoria pode atuar como um primeiro passo para uma relação mais próxima e mais complexa e, no exercício dela, os pais poderão entender melhor o funcionamento geral da escola.

Epstein ( 1987) e Bastiani ( 1993) defendem que o envolvimento de pais com a escola deveria ser sempre iniciativa das escolas, sem desprezarmos, porém, aquelas iniciativas vindas deles. Uma das razões para isto é que a comunidade de pais é composta por opiniões diversificadas, tanto sobre o mundo que os rodeia como sobre o que eles sabem sobre a escola. Além disso, e de acordo com o que pudemos concluir neste estudo, os pais têm necessidades diferentes e, portanto, demandas e interesses diferentes. Gostariam que a escola tomasse a iniciativa e sugerisse a eles formas de como fazer as coisas, tanto para a relação escola-família quanto para o seu envolvimento com a educação escolar, a escola e principalmente para as crianças. Tendo o conhecimento dos potenciais dos pais (em áreas de interesse), a escola pode se organizar para que a relação escola-família, a partir do que conhece de seus alunos e pais, seja desenvolvida na direção mais adequada.

A falta de conhecimento das possibilidades e oportunidades, que ambas instituições podem oferecer umas as outras, contribui muitas vezes para o afastamento das esferas sobrepostas e para as negociações sem sucesso e frustradas. $\bigcirc$ desentendimento entre os pais e a escola é, na maioria das vezes, decorrente da falta de contato, informação e diálogo.

\section{COMUNICAÇÃO}

A comunicação, seja ela feita por escrito ou oralmente, está sempre no centro de qualquer "negociação". Na relação escola-família, esta é também de extrema importância. Tanto para a categoria "ajuda" como para a categoria "envolvimento", a comunicação é a base de tudo que pode ser criado e desenvolvido entre os pais e a escola. $\bigcirc$ nosso grupo enfatizou bastante a importância de poder se comunicar com maior freqüência e abertamen- 
te com a escola e vice-versa. Estavam particularmente preocupados com a forma como alguns problemas surgiam, devido à falta de entendimento e de comunicação entre eles e os profissionais. A comunicação pode ser classificada como um "instrumento" que viabiliza a relação escola-familia; que poderá agir como um facilitador e promotor da relação.

É comum que todos os pais recebam mensagens vindas da escola. No nosso estudo, na maioria das vezes as mensagens vinham por escrito e, com menos freqüência, oralmente. As reuniões e as circulares (os métodos mais usados pelas escolas para contatar os pais) tinham sempre um caráter informativo, que cobriam assuntos relacionados à rotina prática do dia, o calendário escolar, incluindo os eventos sociais, material e uniformes e regras de escola. Muito raramente esses encontros e circulares tratavam de assuntos relacionados ao desenvolvimento das crianças, ao processo de ensino/aprendizagem, como as crianças estavam melhorando no rendimento escolar e no aspecto social e cognitivo. Os pais eram contatados individualmente somente em situações extremas para tratar de assuntos relacionados com dificuldades e problemas que eles (os professores) ou as crianças estavam enfrentando. Também disseram que havia horários designados para encontros individuais com os professores mas que estes eram limitados e, às vezes, muito concorridos, não havendo tempo suficiente para cada situação. No geral, as formas de comunicação variam muito de escola para escola e de professor para professor e, ainda, de caso para caso, assim como os conteúdos das mensagens e abordagens utilizadas.

O grupo todo manifestou um grande interesse, independentemente de estar disponível ou não, para prestar "ajuda", ou ficar "envolvido" com a escola, em saber mais sobre o que se passa nela e com os seus filhos: gostaria de receber mais informações, de maneira simples e clara, sobre o processo escolar. Quer exemplos práticos, de como e o quê as crianças aprendem em cada matéria para que possam entender melhor os métodos usados em sala de aula e o que os filhos tem de fazer para obter resultados positivos. $\bigcirc$ grupo gostaria também que nas reuniões, dúvidas (por vezes básicas) fossem esclarecidas sem o uso de jargões; um exemplo muito mencionado foi o uso da palavra "construtivismo" para justificar as ações dos professores em sala de aula, cujo significado e implicações não eram entendidos pelos pais. Os pais desejam sentir-se bem, seguros, confiantes e sem constrangimentos para se aproximarem dos professores, usando linguagem simples e objetiva, para os ajudar antes que os problemas surjam.

Eu gostaria que a escola me dissesse o que eles estão fazendo, como eles desenvolvem as atividades em termos práticos para que meu filho aprenda o necessário...ou até mesmo me mandassem uma avaliação resumida do seu progresso em sala de aula junto com o boletim... Eu queria saber mais sobre a escola, o que nós sabemos é muito superficial... às vezes eles têm dificuldades lá e nós nem sabemos... (mãe n. I5, escola n. 6).

Atkin e Bastiani ( 1984), Bastiani ( 1978, 1986), Dye ( 1989), Epstein e Dauber ( 199 |), Dauber e Esptein (1993), Finders e Lewis (1994) e ainda outros dedicaram grande parte de 
seus trabalhos para a investigação sobre as formas de comunicação utilizadas pelas escolas em vários contextos diferentes. Há inúmeras formas e maneiras para a comunicação com os pais, e estas dependem muito da comunidade a ser servida. No entanto, eles recomendam que haja muito cuidado na preparação de materiais informativos para os pais e que geralmente a fórmula mais eficaz está em prepará-los de maneira simples, com vocabulário de fácil entendimento e de conteúdo básico e explicativo. Para o contexto brasileiro, o cuidado deve ser ainda maior na preparação de tais materiais, dadas as diferenças socioeconômicas e culturais do país. Temos de aprender a desenvolver estratégias diferentes, para que possamos servir aos pais (e já pensando em atrair a atenção dos pais e não só das mães) e incluí-los na educação escolar dos seus filhos. É preciso lembrar que essas formas de comunicação também têm como objetivo facilitar a adaptação das crianças à escola e ao processo de aprendizagem. Precisamos abrir a escola aos pais e contar com eles para nos ajudar a desempenhar nosso papel dentro e fora da escola, visando sempre melhores resultados.

Q Quadro 5 resume a relação escola-família vista por este grupo de vinte mães e uma avó de crianças de $4^{\mathrm{a}}$ série de algumas escolas estaduais em Belo Horizonte:

QUADRO 5

A VISÃO DOS PAIS

\begin{tabular}{|c|c|c|c|}
\hline & Estrutura & Visto como & Atitude para \\
\hline Envolvimento & $\begin{array}{l}\text { Relacionado com o } \\
\text { curriculum, ensino e } \\
\text { aprendizagem }\end{array}$ & \multirow{3}{*}{$\begin{array}{c}\text { Sendo } \\
\text { obrigação } \\
\text { e iniciativa } \\
\text { da escola }\end{array}$} & $\begin{array}{l}\text { Posiçao incerta; desco- } \\
\text { nhecem maneira para } \\
\text { execução da categoria. }\end{array}$ \\
\hline Ajuda & $\begin{array}{l}\text { Relacionada com } \\
\text { aspectos práticos } \\
\text { da escola }\end{array}$ & & $\begin{array}{l}\text { Prontos para contribuir } \\
\text { e prestar ajuda quando } \\
\text { a escola requisitar. }\end{array}$ \\
\hline Comunicação & $\begin{array}{l}\text { Um instrumento } \\
\text { para a relação }\end{array}$ & & $\begin{array}{l}\text { Espera-se que melhore } \\
\text { em conteúdo e seja mais } \\
\text { freqüente. }\end{array}$ \\
\hline
\end{tabular}

\section{CONCLUSÃO}

A relação escola-família pode ser descrita como todas as formas de contato entre as escolas e as famílias (professores e pais) e vice-versa. Como Epstein coloca, existem vários níveis e maneiras de a escola e a família se relacionarem produtivamente, visando sempre o bem-estar e o sucesso escolar das crianças. Infelizmente, ainda não podemos contar com uma fórmula precisa que auxilie todas as escolas (e pais) e dê conta de diferentes contextos, para colocar em prática o que é descrito pelas tipologias (em suas diversas maneiras de envolvimento de pais). No entanto, é ponto pać́fico que a escola não pode excluir os pais do processo escolar e nem dividir as responsabilidades de pais e de profissionais da educação. $\bigcirc$ 
envolvimento de pais, devido ao seu caráter mutável (em relação à comunidade que servimos, mais precisamente os diversos tipos de estruturas familiares hoje existentes na sociedade e aos estágios de desenvolvimento das crianças), deve, entretanto, acompanhar as mudanças que ocorrem não só na sociedade em geral, como também as demandas das três partes envolvidas - escola, família e crianças. Para atingir níveis mais complexos de relacionamento, o processo pode, muitas vezes, ser lento, porém produz resultados positivos.

Lareau (1987), ao pesquisar o envolvimento de pais em escolas que atendem a populações de classes diferentes, concluiu que a diferença entre as classes sociais é uma variável forte, que influencia o processo de envolvimento dos pais. Classe social é, sem dúvida, um fator relevante para a relação escola-família, mas não é, e nem pode ser, o determinante da inexistência do contato entre eles. Não podemos desprezar o fato de que na comunidade de pais encontraremos diversos backgrounds e por isso os pais executarão tarefas de maneiras diferentes e menos ou mais complexamente. $\bigcirc$ que não podemos fazer é justificar as nossas "não tentativas" de incluí-los no processo devido a uma falta de conhecimento daquelas várias maneiras de executar (tanto professores como pais) uma mesma tarefa. É importante ainda ressaltar que existem níveis diferentes de envolvimento. Não podemos esperar que todos os pais se envolvam da mesma forma, porque existem também outras variáveis que são importantes neste processo (disponibilidade, capacidade intelectual, situação psicológica, e ainda, mais importante, a vontade da criança) e que todas as escolas desenvolvam o mesmo programa.

Nossos resultados mostram que nossos pais (neste caso representados por mães) gostariam de saber mais sobre o funcionamento geral da escola, e desejariam que suas regras assim como as da sala de aula se tornassem mais conhecidas. Por exemplo, a disciplina e o comportamento das crianças, que também foram pontos mencionados, sobre os quais gostariam de ter maiores esclarecimentos e como agir conjuntamente para resolver e evitar problemas. Podemos concluir que a falta de conhecimento das possibilidades de existência desta relação e dela se tornar mais produtiva é um dos fatores determinantes da má situação brasileira em relação ao contato entre as escolas e os pais. Estes resultados são semelhantes àqueles de Carvalho (1989), no que tange ao isolamento das iniciativas tanto da escola como da família. Zanella et al (1997) também ressalta que, em decorrência do desencontro de opiniões entre professores e pais, e do "desconhecimento por parte dos professores, equipe pedagógica, equipe administrativa e de apoio, do que pensam os pais sobre a escola e o papel que esta desempenha" (p. I 5 I) a participação dos pais continua limitada e restrita a poucos contatos durante o ano.

É também fundamental ressaltar que, apesar de não termos avaliado as diferenças e semelhanças de opiniões entre as diferentes estruturas familiares da nossa amostra devido ao seu pequeno número, esta variável deve ser considerada e pontuada ao se por em prática os tipos de envolvimento. Souza (1997) analisa o impacto que as mães trabalhadoras podem ter nas relações entre escola e mães (como a autora ressalta, o papel da mãe, seja ela de 
qualquer estrutura familiar, ainda é o de orientar os filhos para a escolarização) e chama a atenção para entendermos melhor os contextos de vida tanto das mães quanto dos professores. Como já foi enfatizado, cada estrutura familiar e cada criança tem necessidades diferentes e, portanto, é necessário avaliar as condições de implantação das práticas para obtenção de resultados melhores.

Nosso próximo passo é estudar o ponto de vista dos/as professores/as das mesmas escolas com relação ao envolvimento de pais com a escola e a educação escolar, para podermos planejar as estratégias a serem usadas no futuro. Como Zanella et al (1997) ressaltam, a literatura brasileira, neste tópico, ainda é escassa e, portanto, mais estudos sobre a atuação dos pais (ressaltando agora a inclusão de homens) em nossas escolas é de extrema importância.

\section{REFERÊNCIAS BIBLIOGRÁFICAS}

ATKIN, J., BASTIANI, J. Listening to parents. an approach to the Improvement of homeschool relations. Beckenham: Croom-Helm, 1984.

. Home and school: a study guide. Nottingham: Nottingham University School of Education, 1984.

. Preparing teachers to work with parents: a survey of initial training. Nottinham: Nottingham University School of Education, 1984.

BASTIANI, J. Working with parents. a whole-school approach. Routledge, 1993.

. Written communication between home and school. A Report by the Community

Education Working Party. Nottingham: Nottingham University, 1978.

. Your home/school links. Keyworth, Notts.: New Education Press, 1986.

BRANDT, R. On parents and schools: a conversation with Joyce Epstein. Educational Leadership, n.47, p.24-7, 1989.

BRYANT, P. Children and arithmetic. J. Child Psychology and Psychiatry, v.36, n. I, p.3-32, 1995.

BURGESS, R. In the field: an introduction to field research. George Allen \& Unwin (Publishers) Ltd., 1984.

CARVALHO, M. P. Um invisível cordão de isolamento: escola e participação popular. Cadernos de Pesquisa, n.70, p.65-73, ago. 1989.

CYSTER, R., CLIFT, P., BATTLE, S. Parental involvement in primary schools. NFER Publishing Company, 1979.

DAUBER, S., EPSTEINJ. Parents' attitudes and practices of invo/vement in inner-city elementary and middle schools. [Paper presented at the annual meetings of the American Educational Research Association], San Francisco, March, 1989. 
- Parents' attitudes and practices of involvement in inner-city elementary and middle schools. In: CHAVKIN, N. F. (ed.), Families and schools in a pluralistic society. Albany: State University of New York Press, 1993. p. 53-7I.

DYE, J. Parental involvement in curriculum matters: parents, teachers and children working together. Educational Research, v. 31, n. I, p.20-33, 1989.

EPSTEIN J. Parents' reactions to teacher practices of parental involvement. The Elementary School Journal, v. 86, p.277-94, 1986.

. School and family connections: theory, research, and implications for integrating sociologies of education and family. Marriage and Family Review, v. I-2, p. 99-126, 1990.

. School and family partnerships. In: ALKIN, M. (ed.) Encyclopedia of educational research. 6th Edition. New York: MacMillan, 1992. p.|I39-I5I.

. Toward a theory of family-school connections: teacher practices and parent involvement. In: HURRELMANN, K., KAUFMANN, F., LOSEL, F. (eds.). Social intervention: potential and constraints. New York/Berlin: Aldin/de Gruyter, 1987.

EPSTEIN, J., BECKER, H. Parent involvement: a survey of teacher practices. The Elementary School Journal, v.83, n.2, p.85-102.

. Teachers reported practices of parent involvement: problems and possibilities. The Elementary School Journal, v.83, n.2, p. 103-13, 1982.

EPSTEIN, J., CONNORS, L. Schools and family partnerships in middle and high schools. Practitioner, 1992.

EPSTEIN J., DAUBER, S. School programs and teachers practices of parent involvement in inner-city elementary and middle school. The Elementary School Journal, v.9I, n.3, p.289-303, 1991.

. Teacher attitudes and practices of parent involvement in inner-city elementary and middle schools. Baltimore: Johns Hopkins University, Center for Research on Elementary and Middle Schools, 1989. (CREMS Report, 32)

EPSTEIN, J., SALINAS, K. School and family partnerships. survey of parents in elementary and middle grades. Johns Hopkins University, Center on Families, Communities, Schools and Children's Learning, Baltimore, Maryland, 1993.

School and family partnerships. survey of teachers in elementary and middle grades. Johns Hopkins University, Center on Families, Communities, Schools and Children's Learning, Baltimore, Maryland, 1993.

FALCÃO FILHO. Participação dos pais no processo educacional: desafio ou impossibilidade? Revista Pedagógica, Belo Horizonte, v.7, n.42, p.8, 1989. 
FERRAZ, C. Esses pais de alunos. Nova Escola, n.2, p.48-5I, 1986.

FINDERS, M., LEWIS, C. Why some parents don't come to school. Educational Leadership, v.5I, n.8, p.50-4, - 1994.

HADDAD, L. A relação creche-família: relato de uma experiência. Cadernos de Pesquisa, n.60, p.70-8, fev. 1987.

HANNON, P., JACKSON, A. Educational home visiting and teaching reading. Educational Research, v.29, n.3, p.182-91, Nov. 1987.

HEWISON, J., TIZARD, J. Parental involvement and reading attainment. Br. J. Ed. Psychology, v.50, p.209-15, 1980.

JOWETT, S., BAGINSKY, M. Parents and education: a survey of their involvement and a discussion of some issues. Educational Research, v.30, n. I, Feb. 1988.

JOWETT, S., BAGINSKY, M., MACNEIL, M. M. Building bridges: parental involvement in schools. NFER-NELSON Publication, 1991.

LAREAU, A. Social class differences in family-school relationships: the importance of cultural capital. Sociology of Education, v.60, p.73-85, 1987.

MORTIMORE, P. et al. School matters: the junior years. Wells Open Books, 1988.

PINTO, C. Reunião de pais: uma experiência no Colégio Imaculada Conceição. Revista Pedagógica, Belo Horizonte, v.3, n. 14, p.32-3, 1985.

SMITH, T. Parents and pre-school. London: Grant Maclntyre, 1980.

SMOLKA, A. Família e escola: o que as crianças percebem e nos dizem. Leitura: Teoria e Prática, Campinas, v.8, n.13, p.33-6, 1989.

STACEY, M. Parents and teachers together. Open University Press, 1991.

SOUZA, B. P. Mães contemporâneas e a orientação dos filhos para a escola. In: MACHADO, A. M., SOUZA, M. P. R. (org.). Psicologia escolar: em busca de novos rumos. (Coleção Psicologia e Educação).

TIZARD, B., MORTIMOR, P., BURCHELL, B. Involving parents in nursery and infant school:a resource book for teachers. London: Grant Mclntyre, 1981.

TIZARD, J., SCHOFIELD, W., HEWISON, J. Collaboration between teachers and parents in assisting children's reading. Br. J. Ed. Psychology, v.52, p. I- 15, 1982.

VIANNA, C. Divergências mas não antagonismos: mães e professoras das escolas públicas. Cadernos de Pesquisa, n.86, p.39-47, ago. 1993.

WOLFENDALE, S. Empowering parents and teachers. working for children. Londres: Cassell, 1992. 
. Parental involvement in children's development and education. London: Gordon and Breach, 1983.

ZANELLA, A. et al. Participação dos pais na escola: diferentes expectativas. In: ZANELLA, A., SIQUEIRA, M. J. T., MOLON, S. I. (orgs.). Psicologia e práticas sociais, Porto Alegre: ABRAPSOSUL, 1997. 